\title{
A INCLUSÃO DA ARTE CONTEMPORÂNEA NO ENSINO DE ARTES
}

\author{
Marina Pereira de Menezes ${ }^{1}$
}

\section{Resumo}

O texto apresenta reflexões acerca do ensino de artes na atualidade, destacando conceitos e referências. Como proposta para um debate acerca de novos fundamentos para este ensino, a autora discute sobre uma prática atenta aos aspectos contemporâneos da arte e da cultura, onde a abertura, investigação, experimentação e pluralidade são conceitos-chave.

Palavras-chave: Ensino de Artes, Arte Contemporânea e Cultura contemporânea

\begin{abstract}
This article presents reflections about art education in the present moment, pointing concepts and references. As a proposition for a debate on new fundaments for this education, the author discusses about a new practice concerned with artistic and cultural contemporary aspects, where openness, investigation, experimentation and plurality are key-concepts.
\end{abstract}

Keywords: Art Education, Contemporary Art and Contemporary Culture

\section{Problematizando o ensino de artes}

Desde a década de 80 o debate sobre o ensino de artes tornou-se intenso. Diversas mudanças positivas ocorreram, entretanto, as atuais perspectivas teóricas ainda parecem indicar uma necessidade de mudança. A cada dia surgem mais referências, algumas oriundas dos mais diversos campos de conhecimento. Mas uma problemática parece manter-se constante: a da distinção entre teoria e prática.

Apesar da área possuir um PCN (Parâmetros Curriculares Nacionais) específico, a divergência de objetivos, conteúdos e práticas de uma escola para outra é, por vezes, muito grande. Mesmo a freqüência semanal da disciplina não é homogênea (restringindo-se majoritariamente à uma aula semanal). Apesar da LDB (Lei de Diretrizes e Bases n 9.394, de 20 de dezembro de 1996) ter estabelecido sua obrigatoriedade como componente curricular da educação básica, muitas escolas não oferecem a disciplina para todas as séries, ou a substituem por Desenho Geométrico quando os alunos chegam ao $2^{\circ}$ segmento do ensino fundamental.

Paralelo a isto, enquanto teóricos discutem métodos, técnicas e práticas, os professores destacam a dificuldade de desenvolver-las no cotidiano das aulas de artes. As dificuldades encontradas por esses professores são diversas, vão desde a falta de apoio do ambiente escolar e a desvalorização da matéria (e suas diversas implicações), até o pouco tempo das aulas e sua freqüência semanal, chegando, ao final, ao próprio desinteresse dos alunos. Os livros didáticos destinados ao professor de artes apresentam, majoritariamente, técnicas e propostas prontas para serem transpostas para as aulas, mas não se preocupam em discutir sobre essas práticas (seus significados, objetivos, possibilidades de desdobramento em outros trabalhos, sua continuidade e ligação à história da arte...). É curioso perceber que alguns livros didáticos (cheios de atividades e temas) apresentam em suas partes introdutórias, conceitos e objetivos que não parecem estar presentes nas propostas de trabalho - outra diferença entre teoria e prática.

${ }^{1}$ Universidade do Estado do Rio de Janeiro - UERJ. 
De modo geral, os trabalhos desenvolvidos pelos alunos nas aulas de arte, parecem restringir-se a realização de trabalhos técnicos (onde o professor introduz uma técnica e os alunos produzem ou reproduzem trabalhos a partir das mesmas) ou a atividades "divertidas", em que explorando materiais ditos "característicos da arte", pretende-se ensinar arte. $\mathrm{O}$ foco das aulas é basicamente o resultado do trabalho. $\mathrm{O}$ processo desenvolvido não tem a mesma relevância, ao menos que se analise como o aluno chegou a determinado resultado. Erros, experimentações, investigações e tentativas não são focos de discussão ou análise.

Nesse dia-a-dia das aulas, o plano de aula consiste no desenvolvimento de propostas e trabalhos desarticulados entre si, sem continuidade e sem tempo de reflexão. A formulação das propostas é responsabilidade total do professor (por vezes envolvido em projetos interdisciplinares), que assume o papel de "ser criativo", sempre inventando novos temas. Esse papel exaustivo de sempre estar trazendo novas idéias dificulta a definição de trabalhos em continuidade, e ainda tira a possibilidade dos alunos criarem e desenvolverem suas propostas.

De maneira geral, muitas são as diretrizes tomadas pelos professores e teóricos do ensino de artes. Multiculturalidade, arte-terapia, livre expressão, educação inclusiva, entre outras. Muitas dessas propostas são voltadas para os alunos e sua inserção sócio-cultural, seu desenvolvimento cognitivo, motor ou psicológico. Outras, focalizando primeiramente o desenvolvimento estético do aluno, têm a arte e sua produção como foco da experiência a ser desenvolvida em aula. Os objetivos defendidos pelos professores variam de acordo com esses posicionamentos - que não são excludentes, podendo um mesmo professor ou teórico, articular objetivos relacionados ao desenvolvimento estético, e ao ambiente cultural do aluno.

Vincent Lanier destaca que "o que a arte educação precisa é de um forte conceito central. A fragmentação de idéias que hoje impera no ensino de arte não é em si perniciosa mas seria bem mais produtivo um quadro conceitual coeso" (LANIER, 1997, p.43). O que o autor chama de fragmentação, se refere à diversidade de conceitos e referências que são perceptíveis nas metodologias adotadas e defendidas por professores e teóricos, que provém de diversas áreas de conhecimento, apresentando, assim, diferentes pontos de vista, valores e contribuições.

Mas, como destaca o autor, a fragmentação não é em si perniciosa. A diversidade de linhas teóricas e de pesquisa pode ser frutífera pois, permite uma ampliação do alcance da atividade artística para outras formas de desenvolvimento do aluno. Mas, não devemos nos distanciar de um conceito forte, que seja atento ao referencial artístico. Para Lanier, o foco do professor de artes deve estar sempre no progresso dos procedimentos estéticovisuais $(1997$, p.45).

Desta maneira, defende-se que as propostas desenvolvidas pelos professores de artes devem buscar promover contatos, interações, reflexões e conhecimentos ligados à arte e as suas diversas possibilidades estéticas, culturais e históricas. Para Lanier (1997), a problemática característica da pluralidade de referências e metodologias não se encontra nas diferentes opiniões e propostas, mas na elaboração de referenciais para as aulas de artes, que sejam alheios às manifestações artísticas.

As contribuições extra-artísticas não devem, entretanto, ser excluídas, mas trabalhadas a partir de suas possíveis contribuições para um constante desenvolvimento das questões relativas ao ensino da arte. Quanto aos objetivos extra-artísticos, os mesmos 
podem ser tidos como desdobramentos da proposta, mas não como fundamentos para a mesma.

Refletindo sobre a possibilidade de se formular uma proposta de trabalho atenta à arte, nas suas especificidades como campo de conhecimento autônomo, discutir-se-á, em seguida, uma abordagem para as aulas de arte que tenha como foco a Arte Contemporânea.

\section{A inclusão da arte Contemporânea no ensino de artes: relacionando produção e ensino de artes}

Considerando-se a maior parte das práticas desenvolvidas nas aulas de artes, pode-se facilmente perceber a diferença entre o que se produz atualmente em arte e o que se apresenta como arte nas escolas.

As constantes mudanças que levaram ao movimento artístico contemporâneo incluem uma série de re-significações, transformações e, principalmente, supressão de valores e regras. O aspecto transgressor dessa nova arte abala os limites da definição do que é arte, e coloca o público, o artista e o crítico de arte em novos papéis e sob novas indagações... Afinal, o que é arte?

Percebemos no atual momento artístico uma pluralidade de experimentações, uma profusão de estilos, formas e programas (ARCHER, 2001). Os processos artísticos ganham força, testam-se materiais, limites, idéias e conceitos.

Não é mais possível definir um valor único que seja comum às obras, não há regras, materiais, métodos e técnicas que possam a priori caracterizar a obra de arte, assim como as antigas classificações de escultura, pintura e arquitetura ${ }^{2}$ parecem não mais dar conta das diferentes manifestações que vem sendo desenvolvidas pelos artistas contemporâneos.

Desde as Vanguardas no início do século XX os limites da arte foram sendo transpostos, as formas mudaram, a natureza deixou de ser o modelo, e a representação da mesma deixou de um objetivo. As experimentações voltaram-se sobre novos elementos. Cor, forma e expressão ganham diferentes abordagens pelas diferentes vanguardas.

As vanguardas, em seus manifestos e na sua produção, mostravam caminhos pelos quais acreditava-se produzir uma arte de ruptura. Como Mammi destaca: "Toda obra relevante de arte moderna não se põe como a primeira de uma nova fase, mas como a última, aquela além da qual não se pode ir" (2001, p.82).

Em meados do século, quando o centro de artes mundial transfere-se da Europa para os Estados Unidos, a postura crítica intensifica-se para outros meios e formas. Os anos 50 - 70 são marcados não só pelo Expressionismo abstrato de Jackson Pollock ou pelas esculturas de Anthony Caro, mas também pela série de experimentações, que ampliam e questionam os limites da arte. Os primeiros, apresentam maior influência e estão mais próximos a critica de Clement Greenberg - a autocrítica e a autonomia das formas e têm maior influência até os anos 60. Os segundos, cuja maior presença é nos anos 60-70, questionam não só o status das obras associadas à crítica de Greenberg, como também trazem para o discurso artístico, reflexões políticas, sociais e históricas.

O questionamento acerca de práticas e métodos esteve, de certa maneira, dentro de todas as manifestações artísticas que se propunham a produzir mudanças. A discussão sobre as formas, os meios, espaços, temas e sistemas englobam toda a produção e história da arte. O novo parece ser uma tradição da própria arte (ROSEMBERG, 2004).

\footnotetext{
2 Sobre a abertura das classificações artísticas ver Rosalind Krauss em: A Escultura no Campo Ampliado In: Revista Gávea, n.1. Rio de Janeiro: 1994.
} 
Entretanto, dentre as manifestações artísticas atuais, a multiplicidade de práticas, materiais, meios, referências e conceitos demonstram indeterminadas possibilidades de experimentação e produção. O campo da arte tornou-se aberto.

A abertura, para Umberto Eco é "entendia como uma ambigüidade fundamental da mensagem artística, é uma constante em qualquer obra em qualquer tempo" (p.25, 1997), mas também como um conceito característico das obras contemporâneas, que permeia a sua realização.

Esses novos elementos trabalhados pela arte contemporaneamente implicam diferentes relações com o público. Henry Geldzahler, discorrendo sobre esta relação durante o séc. XX, destaca que "A historia da arte Moderna é a história da perda progressiva do público de arte. A arte tornou-se acentuadamente a preocupação do artista e a perplexidade do público" (2004, p.76). Perda de um público, cabe destacar, formado por colecionadores cultos, por membros da aristocracia... Atualmente, esta relação ainda parece problemática. O público da arte ainda é especializado e os valores artísticos procurados pela maior parte do público nas obras, não condizem com as novas propostas e experimentações contemporâneas.

Como as questões da arte contemporânea estão distantes das práticas desenvolvidas nas aulas de artes, as possibilidades de intensificar tal relacionamento dentro do espaço escolar são eliminadas. Se trabalhadas juntas, possibilitar-se ia um maior debate perante as obras, levando à produção de conhecimentos sobre o que se produz sobre arte hoje. A abordagem das produções contemporâneas, analisadas em perspectiva histórica, crítica, experimental e investigativa, poderia estimular a percepção da arte, pelos alunos, como uma manifestação em processo, reflexiva, autocrítica, autônoma mas também atenta ao seu tempo. Eco partilha tais idéias quando destaca que:

Perguntamo-nos então se a arte contemporânea, educando para a contínua ruptura dos modelos e dos esquemas - escolhendo para modelo e esquema a efemeridade dos modelos e dos esquemas e a necessidade de seu revezamento, não somente de obra para obra, mas dentro de uma mesma obra - não poderia representar um instrumento pedagógico com funções libertadoras (ECO, 1997, p.14)

Tendo a abertura como valor, e a multiplicidade de práticas como característica, a arte contemporânea pode levar os alunos a desenvolverem trabalhos e poéticas pessoais, buscando a análise e a percepção de sutilezas e especificidades, ao invés da imposição de valores únicos como resultados a serem atingidos. Dando maior atenção ao processo em detrimento do resultado, articulando o questionamento, a investigação, as descobertas e a continuidade, acredita-se que será possível desenvolver trabalhos significativos tanto para os alunos quanto para os professores.

A inclusão da arte contemporânea no ensino de artes implica tanto uma resignificação de métodos, como a adoção de uma postura aberta pelo professor, que deve atuar estimulando os alunos a desvendar-se sobre o processo artístico tal qual o artista o faz, articulando seus conhecimentos, buscando soluções, destacando objetivos... Posicionando-se desta maneira, as obras de artes poderão ser analisadas segundo as experiências realizadas e vivenciadas pelos alunos.

A arte contemporânea não é alheia às questões referentes à contemporaneidade. O sentido da arte está "dentro das demais expressões dos objetivos humanos, e dos modelos de vida a que essas expressões, em seu conjunto, dão sustentação" (GEERTZ, 1997, p.145). Desta maneira, promovendo e defendendo a pluralidade, poder-se-á abrir 
espaço para as referências artísticas trazidas pelos alunos para a sala de aula. É neste aspecto que a experiência desenvolvida pode ultrapassar a experimentação artística e atuar sobre o desenvolvimento sócio-cultural os alunos.

A Cultura contemporânea entendida como momento em as identidades caracterizam-se como fragmentadas, caracterizada pela multiculturalidade, pelas mudanças paradigmáticas, e pelas inovações tecnológicas impulsiona e é impulsionada pelo fenômeno da globalização.

É em tempos de globalização, quando o mundo torna-se mais interconectado, diminuindo distâncias e aproximando as pessoas, que o desenvolvimento de uma consciência da diversidade - onde o conhecimento, o respeito e a tolerância superpasse as posturas reacionárias - que a educação ganha importância como meio de se estimular uma consciência democrática. $\mathrm{O}$ ensino de artes atento às diferenças como possibilidade de manifestação, pode atuar sobre esta nova condição cultural contemporânea, estimulando a produção de conhecimento, ao invés da defesa de valores únicos tidos como verdadeiros.

A anterior discussão sobre o ensino de artes na atualidade abriu espaço para se repensar um conceito, que atento à arte, pudesse ser produtivo para a prática escolar artística. No trabalho em questão, buscou-se através da arte contemporânea, propor um caminho para o desenvolvimento de trabalhos educacionais, que tendo como base a arte, como campo de conhecimento específico, pudesse desenvolver, como objetivo principal, experiências artísticas significativas, com continuidade e reflexão. Sendo as contribuições para a vida e para a postura dos alunos como sujeitos sociais e culturais, possíveis desdobramentos positivos para outros campos de conhecimento.

\section{Bibliografia}

ARCHER, Michael. Arte Contemporânea: Uma história concisa. São Paulo: Martins Fontes, 2001.

GELDZAHLER, Henry. O público de arte e o crítico. BATTCOCK, Gregory (org). A Nova arte. São Paulo: Perspectiva, 2004.

ECO, Umberto. Obra aberta.São Paulo: Perspectiva, 2003.

GEERTZ, Clifford. $A$ arte como sistema cultural. In $\mathbf{O}$ saber local: novos ensaios em antropologia interpretativa. Petrópolis, RJ: Ed. Vozes, 1997.

LANIER, Vincent. Devolvendo a arte à arte-educação. In BARBOSA, Ana Mae (org.) Arte Educação: leitura no subsolo. São Paulo: Cortez, 2002.

MAMMI, Lorenzo. Mortes recentes da arte. In Novos estudos n.60. São Paulo: CEBRAP, 2001.

ROSEMBERG, Harold. O novo como valor. In Objeto ansioso. São Paulo: Cosac e Naify, 2004.

TORNAGHI, Maria. Questôes de arte e da aprendizagem da arte no núcleo de crianças e jovens da escola de artes visuais do Parque Lage. In Atelier guia de Artes Plásticas ano II n¹4. Rio de Janeiro: 1998.

WOOD, Paul, HARRISON, Charles. Modernidade e Modernismo reconsiderados. In Modernismo em disputa: a arte desde os anos quarenta. São Paulo: Cosac e Naify, 1998. 